\title{
A fully automated effervescence-assisted switchable solvent-based liquid phase microextraction procedure: Liquid chromatographic determination of ofloxacin in human urine samples
}

\author{
Christina Vakh ${ }^{\text {a, * }}$, Aleksei Pochivalov ${ }^{\text {a }}$, Vasil Andruch ${ }^{\text {b }}$, Leonid Moskvin ${ }^{\text {a }}$, \\ Andrey Bulatov ${ }^{a}$ \\ ${ }^{a}$ Department of Analytical Chemistry, Institute of Chemistry, Saint-Petersburg University St.Petersburg State University, SPbSU, SPbU, 7/9 Universitetskaya \\ nab., St. Petersburg, 199034 Russia \\ b Department of Analytical Chemistry, University of P.J. Šafárik, SK-04154 Košice, Slovakia
}

\section{H I G H L I G H T S}

- Novel effervescence-assisted switchable solvent-based liquid phase microextraction procedure.

- First fully automated EA-SS-LPME coupled with HPLC-FLD.

- The application of fatty acids as switchable hydrophilicity solvents.

- $\mathrm{Na}_{2} \mathrm{CO}_{3}$ as hydrophilicity modifier, effervescence agent and phase separation intensifier.

- Determination of ofloxacin in human urine samples.

\section{A R T I C L E I N F O}

\section{Article history:}

Received 29 September 2015

Received in revised form

10 December 2015

Accepted 13 December 2015

Available online 17 December 2015

\section{Keywords:}

Effervescence-assisted switchable solventbased liquid phase microextraction

Green analytical chemistry

Flow analysis

Fatty acids

Ofloxacin

Urine
G R A P H I C A L A B S T R A C T

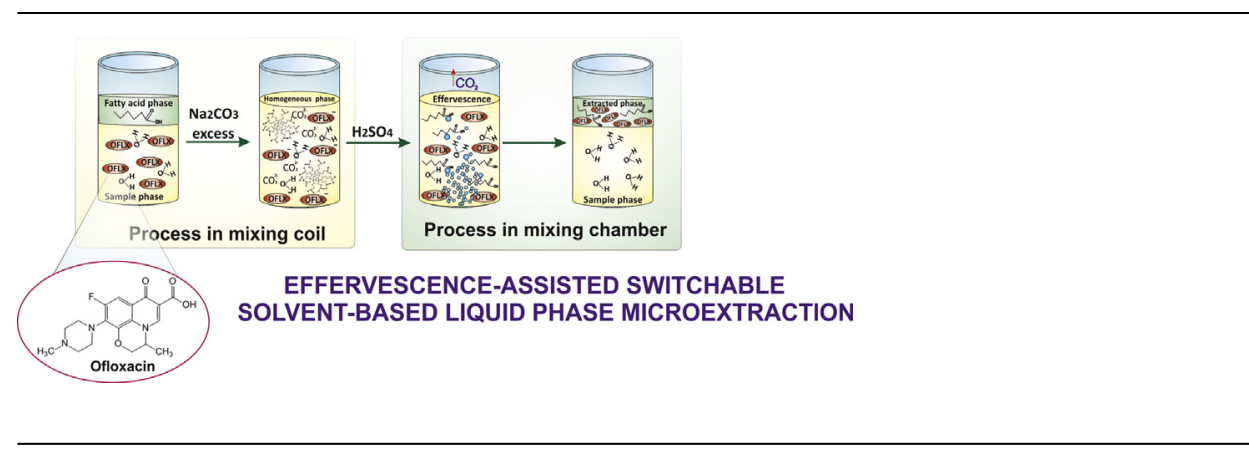

\begin{abstract}
A B S T R A C T
A novel fully automated effervescence-assisted switchable solvent-based liquid phase microextraction procedure has been suggested. In this extraction method, medium-chain saturated fatty acids were investigated as switchable hydrophilicity solvents. The conversion of fatty acid into hydrophilic form was carried out in the presence of sodium carbonate. The injection of sulfuric acid into the solution decreased the $\mathrm{pH}$ value of the solution, thus, microdroplets of the fatty acid were generated. Carbon dioxide bubbles were generated in-situ, and promoted the extraction process and final phase separation. The performance of the suggested approach was demonstrated by the determination of ofloxacin in human urine samples using high-performance liquid chromatography with fluorescence detection. This analytical task was used as a proof-of-concept example. Under the optimal conditions, the detector response of ofloxacin was linear in the concentration ranges of $3 \cdot 10^{-8}-3 \cdot 10^{-6} \mathrm{~mol} \mathrm{~L}^{-1}$. The limit of detection, calculated from a blank test based on $3 \sigma$, was $1 \cdot 10^{-8} \mathrm{~mol} \mathrm{~L}^{-1}$. The results demonstrated that the presented approach is highly cost-effective, simple, rapid and environmentally friendly.
\end{abstract}

(C) 2015 Elsevier B.V. All rights reserved.

\footnotetext{
* Selected paper from Flow Analysis XIII Conference, 5-10 July 2015 in Prague, Czech Republic.

* Corresponding author

E-mail addresses: k.vakh@spbu.ru, kristina-fulmes@mail.ru (C. Vakh).
}

\section{Introduction}

Green analytical chemistry provides development of various analytical procedures and methods with a minimal impact on operators and the environment. Green sample pretreatment 
approaches, especially microextraction, have attracted great attention as they lead inherently to minimum solvent and reagent consumption, and drastic reduction of laboratory wastes [1]. Liquid-phase microextraction (LPME) has grown increasingly popular due to its simplicity, low cost, adaptability to a wide variety of sample types and analytes, as well as, for all major analytical instrumentation [2]. The most frequently used LPME modes are: single-drop microextraction [3,4], hollow-fiber liquid-phase microextraction [5-7], dispersive liquid-liquid microextraction [8], solidified floating organic drop microextraction [9]. All these modes are well described in numerous reviews where the main benefits and drawbacks are presented [1,6,10-13].

Recently, the group of M. Valcarcel suggested two novel approaches for LPME. The first is so-called effervescence assisted dispersive liquid-liquid microextraction (EA-DLLME), in which the extraction process is encouraged by effervescence effect resulting from in-situ carbon dioxide generation [14]. The second is based on the use of so-called switchable hydrophilicity solvents (SHS) for microextraction [15,16]. These solvents (usually amidines and secondary/tertiary amines) can be switched between hydrophobic and hydrophilic forms, depending on the solution composition [17]. Both procedures were further developed also by other authors [18-20]. Just a few months ago, Jen et al. (2015) presented the application of medium-chain fatty acid as extraction solvent (hydrophobic form) for LPME [21]. This solvent can be switched between hydrophobic and hydrophilic forms by the adjustment of $\mathrm{pH}$ of the solution. Thus, in fact, medium-chain fatty acids can also be considered as SHS.

To the best of our knowledge, the above-mentioned procedures were carried out manually, and no automated procedures were reported. Flow analysis can be considered as a superior tool for automation of wide variety of analytical procedures, including microextraction [22-30].

Therefore, the aim of this study was to hyphenate the effervescence-assisted microextraction with switchable hydrophilicity solvents microextraction, and automate the hyphenated procedure. The combined method, effervescence-assisted switchable solvent-based liquid phase microextraction (EA-SS-LPME), assumes using medium-chain fatty acids as extractant. Furthermore, sodium carbonate was used on one hand, to induce conversion of fatty acid from water-immiscible to water-miscible form, and on the other hand, to provide effervescence, while its excess reacts with a mineral acid. In this case, the effervescence increases the efficiency of extraction and phase separation. To demonstrate the efficiency of the suggested approach, the automated EA-SSLPME procedure was applied to determine fluoroquinolone antibacterial agent, ofloxacin (OFLX) as a proof-of-concept analyte in human urine samples, using HPLC with fluorescence detection (HPLC-FLD).

\section{Experimental}

\subsection{Reagents and solutions}

All chemicals and reagents were of analytical grade. Ultra pure water from Millipore Milli-Q RG (Millipore, USA) was used. Fatty acids (nonanoic, hexanoic and pivalic acids), ofloxacin and methanol were purchased from Sigma-Aldrich. Stock solution of $3 \cdot 10^{-3} \mathrm{~mol} \mathrm{~L}^{-1}$ of OFLX was prepared by dissolving the reagent in $1 \mathrm{~mol} \mathrm{~L}^{-1} \mathrm{NaOH}$. The solution was stored in a dark place at $5^{\circ} \mathrm{C}$ and used within 2 months. The solutions of sulfuric $\left(2.5 \mathrm{~mol} \mathrm{~L}^{-1}\right)$, phosphoric (2.5 mol L $\left.\mathrm{L}^{-1}\right)$ and hydrochloric $\left(4 \mathrm{~mol} \mathrm{~L}^{-1}\right)$ acids were prepared by dilution of the concentrated acids with water. $2 \mathrm{~mol} \mathrm{~L}^{-1}$ solution of $\mathrm{Na}_{2} \mathrm{CO}_{3}$ was prepared by dissolving the reagent in water. Phosphate buffer solution ( $\mathrm{pH}$ 6.4) was prepared by mixing $0.05 \mathrm{~mol} \mathrm{~L}^{-1} \mathrm{Na}_{2} \mathrm{HPO}_{4}$ and $0.05 \mathrm{~mol} \mathrm{~L}^{-1} \mathrm{NaH}_{2} \mathrm{PO}_{4}(1: 3, \mathrm{v} / \mathrm{v})$ and adjusted by $1 \mathrm{~mol} \mathrm{~L}^{-1} \mathrm{NaOH}$. Britton-Robinson buffer ( $\mathrm{pH} 4.0$ ) was prepared by mixing $0.12 \mathrm{~mol} \mathrm{~L}^{-1} \mathrm{H}_{3} \mathrm{BO}_{3}, 0.12 \mathrm{~mol} \mathrm{~L}^{-1} \mathrm{H}_{3} \mathrm{PO}_{4}$ and $0.12 \mathrm{~mol} \mathrm{~L}^{-1} \mathrm{CH}_{3} \mathrm{COOH}(1: 1: 1, \mathrm{v} / \mathrm{v})$ and adjusted by $1 \mathrm{~mol} \mathrm{~L}^{-1}$ $\mathrm{NaOH}$.

\subsection{Manifold and apparatus}

The manifold for automated EA-SS-LPME procedure (Fig. 1) consists of two eight-port selection valves (Sciware Systems SL, Spain), a $2.5 \mathrm{~mL}$ syringe pump (Sciware Systems SL, Spain), a peristaltic pump MasterFlex L/S (Cole-Parmer, USA), ensuring reverse flow $\left(0.5-5 \mathrm{~mL} \mathrm{~min}^{-1}\right)$, a mixing coil $(80 \mathrm{~cm}$ length) and a $3 \mathrm{~mL}$ conical tube as a mixing chamber ( $8 \mathrm{~mm}$ in i.d.). A three-way solenoid head valve on-top of the syringe (valve 3 ) enabled the connection to the mixing coil (position ON, activated) or to the waste (position OFF, deactivated). The PTFE tubs of $0.8 \mathrm{~mm}$ in i.d. were used for the entire manifold.

The flow system was coupled with LC-20 Prominence liquid chromatograph (Shimadzu, Japan) with fluorescence detection.

An RF-5301 PC spectrofluorometer (Shimadzu, Japan) equipped with $10 \mathrm{~mm}$ quartz cell was used for the preliminary studies and for the spectrofluorimetric determination of OFLX.

\subsection{Samples and sample preparation}

Human urine samples were collected from fasting and healthy three volunteers in the morning. Before analysis, the urine samples were filtered through a $0.45 \mu \mathrm{m}$ membrane filter. Spiked samples were prepared by addition of calculated volumes of working solutions of OFLX to filtrated blank urine samples so that the volume of resulting solutions was $1 \mathrm{~mL}$. The samples were left to stand for $30 \mathrm{~min}$, to allow interaction between the analyte and the urine matrix. Before analysis, the samples were diluted ten-fold three times, and appropriate aliquot of this solution was used for the analysis.

\subsection{The procedure for automated determination of ofloxacin in human urine samples}

At the first stage, $350 \mu \mathrm{L}$ of $2 \mathrm{~mol} \mathrm{~L}^{-1} \mathrm{Na}_{2} \mathrm{CO}_{3}$ (port 1, valve 1), $1 \mathrm{~mL}$ of diluted urine sample (port 2 , valve 1 ) and $50 \mu \mathrm{L}$ of hexanoic acid (port 3, valve 1 ) were sequentially aspirated to the mixing coil by the syringe pump. While reagents were passing through the mixing coil, formation of homogeneous solution of sodium hexanoate, OFLX and excess carbonate ions took place. Afterwards, the resulting mixture was delivered (port 4 , valve 1 ) into the mixing chamber using the syringe pump. In order to clean the mixing coil from sodium carbonate residues, it was washed out by water (port 5 , valve 1) twice.

$260 \mu \mathrm{L}$ of $2.5 \mathrm{~mol} \mathrm{~L}^{-1} \mathrm{H}_{2} \mathrm{SO}_{4}$ (port 6, valve 1) was aspirated to the mixing coil and delivered into the mixing chamber. Addition of sulfuric acid solution led to conversion of the water-miscible hexanoate ions into hydrophobic hexanoic acid, effervescence-assisted microextraction of OFLX and phase separation.

Afterwards, the aqueous phase was moved to waste (port 7 , valve 1 ), while organic phase remained in the mixing chamber. Then, $450 \mu \mathrm{L}$ of phosphate buffer ( $\mathrm{pH}$ 6.4) and methanol mixture $(1: 1, v / v)$ (port 11 , valve 2 ) was delivered into the mixing chamber by the peristaltic pump for dissolving hexanoic acid, containing the extracted analyte for HPLC analysis. The mixture was mixed by air bubbles (port 12, valve 2) for $20 \mathrm{~s}$.

The obtained solution was aspirated (port 14, valve 2 ) to chromatographic vial using peristaltic pump and analyzed by HPLC-FLD. The fluorescence excitation and emission wavelengths were 293 


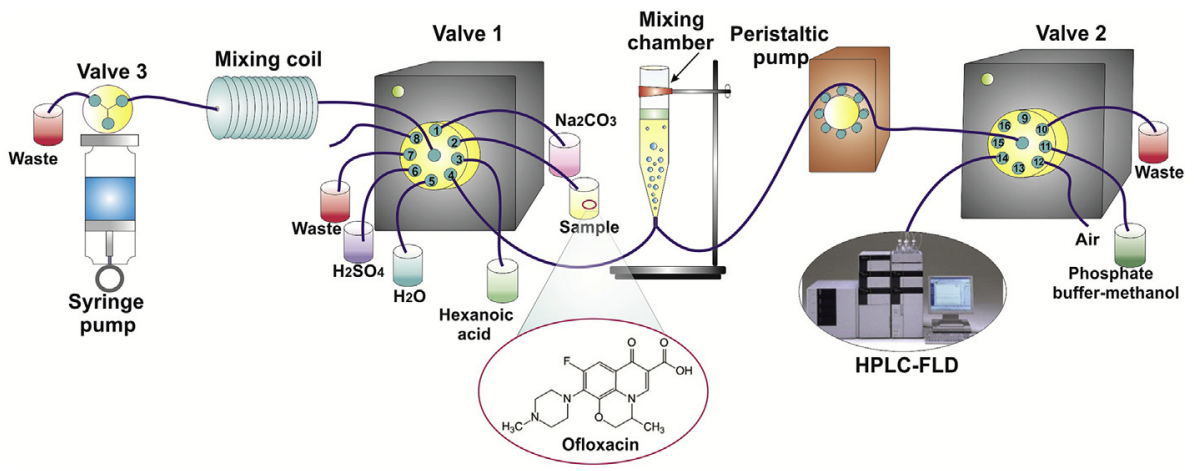

Fig. 1. The manifold for automated EA-SS-LPME system coupled with HPLC-FLD for the determination of ofloxacin in human urine samples.

and $502 \mathrm{~nm}$, respectively. The chromatographic separation was achieved by SUPELCO C18 column $(250 \mathrm{~mm} \times 4.6 \mathrm{~mm}, 5 \mu \mathrm{m})$ with phosphate buffer ( $\mathrm{pH}$ 6.4) and methanol mixture $(1: 1, \mathrm{v} / \mathrm{v})$ at mobile phase flow-rate of $0.7 \mathrm{~mL} \mathrm{~min}{ }^{-1}$. The chromatograph was operated at ambient temperature. The EA-SS-LPME procedure is presented in video.

Supplementary data related to this article can be found online at http://dx.doi.org/10.1016/j.aca.2015.12.004.

\subsection{The procedure for spectrofluorimetric determination of ofloxacin in human urine samples}

$2 \mathrm{~mL}$ of Britton-Robinson buffer (pH 4.0) and $0.4 \mathrm{~mL}$ of sodium dodecyl sulfate (7.5\%) and polyoxyethylene(7.5)nonylphenylether (5\%) solution were added to $10 \mathrm{~mL}$ of urine sample and the mixture was mixed properly and added with $0.6 \mathrm{~g}$ of $\mathrm{NaCl}$. The mixture was centrifuged for $15 \mathrm{~min}$ at $3000 \mathrm{rpm}$ and placed in an ice bath for $10 \mathrm{~min}$. The micellar phase containing the ofloxacin was separated as a solid phase at the bottom of the tube and the aqueous phase was poured off by inversion. The micellar phase in the tube was then diluted with $0.2 \mathrm{~mL}$ of ethanol. The solution was transferred into a quartz cell and the fluorescent intensity was measured $(\lambda \mathrm{ex}=299 \mathrm{~nm}, \lambda \mathrm{em}=496 \mathrm{~nm})[31]$.

\section{Results and discussion}

\subsection{Theoretical considerations of EA-SS-LPME concept}

The mechanism of proposed EA-SS-LPME procedure can be presented by two consecutive steps (Fig. 2). The first step (A and B) includes an addition of hexanoic acid to the aqueous sample and conversion of water-immiscible hexanoic acid to its ionic (hydrophilic) form by addition of sodium carbonate solution. As a result, a homogeneous solution is formed. Approximately, $99.9 \%$ of hexanoic acid is dissociated into its anion form as an anionic surfactant in alkaline sodium carbonate solution (the pKa of hexanoic acid is 4.85 [32]). It should be pointed out that sodium carbonate is added in excess due to its triple role in the extraction process as an alkaline and disperser agent, as well as, a phase separation intensifier.

In the second step, after the addition of sulfuric acid solution (C and $\mathrm{D}$ ), extraction takes place as a result of two chemical processes which occur simultaneously: (1) decreasing $\mathrm{pH}$ induces the conversion of sodium hexanoate to microdroplets of hexanoic acid (in this step OFLX is transferred to organic phase); (2) moreover, the effervescence takes place due to the reaction of sulfuric acid with excess sodium carbonate, and carbon dioxide bubbles generated insitu promote the extraction process and final phase separation. Thus, the whole extraction process proceeds only by simple changing of $\mathrm{pH}$ value.

\subsection{Investigation of appropriate conditions of EA-SS-LPME}

\subsubsection{Effect of extraction solvent type}

Three medium-chain saturated fatty acids (nonanoic, hexanoic and pivalic) were studied. All of them have switchable behavior and can be dissociated into a hydrophilic form at a $\mathrm{pH}$ higher than their pKa. The applicability of these fatty acids for EA-SS-LPME was investigated by adding $50 \mu \mathrm{L}$ of each fatty acid to $1 \mathrm{~mL}$ of $0.5 \cdot 10^{-6} \mathrm{~mol} \mathrm{~L}^{-1}$ of aqueous solution of OFLX, followed by adding $350 \mu \mathrm{L}$ of $2 \mathrm{~mol} \mathrm{~L}^{-1} \mathrm{Na}_{2} \mathrm{CO}_{3}$ and $260 \mu \mathrm{L}$ of $2.5 \mathrm{~mol} \mathrm{~L}^{-1} \mathrm{H}_{2} \mathrm{SO}_{4}$. While



Fig. 2. The EA-SS-LPME process diagram. 



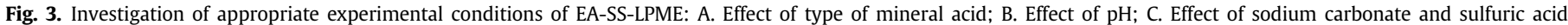
concentrations $\left(\mathrm{C}_{\mathrm{OFLX}}=5 \cdot 10^{-7} \mathrm{~mol} \mathrm{~L}^{-1}\right)$.

using the pivalic acid, poor recovery of fatty acid was observed because of its relatively high solubility. The nonanoic and hexanoic acids have shown satisfactory results of extraction and phase separation efficiency. However, the nonanoic acid needs larger volume of mobile phase to be dissolved. Thus, hexanoic acid was selected for further research.

\subsubsection{Effect of SHS volume}

To find the optimal volume of SHS, $1 \mathrm{~mL}$ of $0.5 \cdot 10^{-6} \mathrm{~mol} \mathrm{~L}^{-1}$ aqueous OFLX solution was extracted by various volumes of hexanoic acid from 25 to $100 \mu \mathrm{L}$ according to the procedure presented in Section 2.4. It was found that the SHS volume less than $50 \mu \mathrm{L}$ led to poor recovery (ESI Fig. A). Thus, the volume of $50 \mu \mathrm{L}$ of hexanoic acid was selected for further studies.

\subsubsection{Effect of volume of sodium carbonate solution}

The addition of $\mathrm{Na}_{2} \mathrm{CO}_{3}$ led to the conversion of hexanoic acid to an anionic surfactant - sodium hexanoate. The higher the volume of $\mathrm{Na}_{2} \mathrm{CO}_{3}$ solution added, the higher the degree of conversion achieved. It is important to take into consideration that sodium carbonate also acts as alkaline, disperser agent, as well as, a phase

Table 1

Influence of some interfering species on the determination of $5 \cdot 10^{-7} \mathrm{~mol} \mathrm{~L}^{-1}$ solution of ofloxacin.

\begin{tabular}{lc}
\hline Species & $\begin{array}{l}\text { Tolerable concentration } \\
\left(\times 10^{-6} \mathrm{~mol} \mathrm{~L}^{-1}\right)\end{array}$ \\
\hline Citric acid, hippuric acid, glucose & 5 \\
Creatine, glycine, uric acid & 50 \\
$\mathrm{Zn}^{2+}, \mathrm{Mg}^{2+}, \mathrm{K}^{+}, \mathrm{SO}_{4}^{2-}, \mathrm{HPO}_{4}^{2-}, \mathrm{NO}_{3}^{-}$ & 50 \\
$\mathrm{Na}^{+}, \mathrm{NH}_{4}^{+}, \mathrm{Ca}^{2+}, \mathrm{Cl}^{-}$ & $500^{\mathrm{a}}$ \\
Urea & $500^{\mathrm{a}}$ \\
\hline
\end{tabular}

\footnotetext{
${ }^{a}$ Highest concentration studied.
}

separation intensifier. To find the optimal extraction efficiency, the volume of $2 \mathrm{~mol} \mathrm{~L}^{-1} \mathrm{Na}_{2} \mathrm{CO}_{3}$ was varied from 250 to $450 \mu \mathrm{L}$. The value of $350 \mu \mathrm{L}$ of $\mathrm{Na}_{2} \mathrm{CO}_{3}$ solution resulted in the maximum EA-SSLPME efficiency (ESI Fig. B), thus, it was chosen for subsequent studies.

\subsubsection{Effect of sample volume}

The sample's volume was varied from 0.25 to $1.5 \mathrm{~mL}$. It was found that, the sample volume of $1 \mathrm{~mL}$ provides effective extraction (ESI Fig. C) and it was chosen as optimal for further experiments.

\subsubsection{Effect of mineral acid type}

A mineral acid was used to convert sodium hexanoate into hydrophobic hexanoic acid, and to provide effervescence (the reaction with excess $\mathrm{Na}_{2} \mathrm{CO}_{3}$ ). Three mineral acids: sulfuric, phosphoric and hydrochloric acids were investigated. According to our results, sulfuric acid significantly increased the extraction efficiency in comparison with hydrochloric or phosphoric acid (Fig. 3A); thus, it

Table 2

Analytical performance of the developed procedure.

\begin{tabular}{ll}
\hline Parameter & \\
\hline Sample volume, $\mathrm{mL}$ & 1.0 \\
Extraction solvent volume, $\mu \mathrm{L}$ & 50 \\
$\mathrm{pH}$ & 6.0 \\
$\mathrm{Na}_{2} \mathrm{CO}_{3}$ concentrations, $\mathrm{mol} \mathrm{L}^{-1}$ & 2.0 \\
$\mathrm{Na}_{2} \mathrm{CO}_{3}$ volume, $\mu \mathrm{L}$ & 350 \\
$\mathrm{H}_{2} \mathrm{SO}_{4}$ concentrations, $\mathrm{mol} \mathrm{L}^{-1}$ & 2.5 \\
$\mathrm{LOD}_{\text {mol L}}^{-1}$ & $1 \cdot 10^{-8}$ \\
Linear range, mol L & $3 \cdot 10^{-8}-3 \cdot 10^{-6}$ \\
Correlation coefficient & 0.997 \\
Time of microextraction, min & 2 \\
RSD, \% (n=5), $3 \cdot 10^{-8}$ mol L & 4.0 \\
\hline
\end{tabular}


Table 3

Results for the determination of ofloxacin in urine samples $\left(\mathrm{n}=3, \mathrm{P}=0.95, \mathrm{~F}_{\mathrm{cr} .}=19, \mathrm{t}_{\mathrm{cr} .}=4.3\right)$.

\begin{tabular}{|c|c|c|c|c|c|c|}
\hline \multirow[t]{2}{*}{ Sample } & \multirow[t]{2}{*}{ Added, $\times 10^{-6} \mathrm{~mol} \mathrm{~L}^{-1}$} & \multicolumn{2}{|c|}{ Concentration of ofloxacin, $\times 10^{-6} \mathrm{~mol} \mathrm{~L}^{-1}$} & \multirow[t]{2}{*}{ F-test } & \multirow[t]{2}{*}{ t-test } & \multirow[t]{2}{*}{ Recovery, \% } \\
\hline & & EA-SS-LPME HPLC-FLD & CE SFL [31] & & & \\
\hline 1 & 40 & $38 \pm 2$ & $42 \pm 4$ & 6.3 & 4.0 & 95 \\
\hline 2 & 80 & $79 \pm 10$ & $83 \pm 11$ & 1.2 & 1.2 & 99 \\
\hline 3 & 125 & $117 \pm 3$ & $122 \pm 8$ & 7.7 & 2.4 & 94 \\
\hline
\end{tabular}

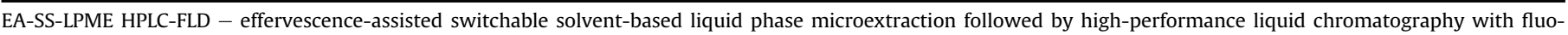
rescence detection with fluorescence detection; CE SFL - cloud-point extraction followed by spectrofluorimetry.

was selected for further studies.

\subsubsection{Effect of $p H$}

The $\mathrm{pH}$ of extraction solution after adding sulfuric acid solution has a great influence on extraction efficiency. It is known that OFLX exists in different forms, depending on $\mathrm{pH}$ [33]. The results in Fig 3B indicate that $\mathrm{pH}$ less than 6.0 result in sharp decrease of extraction efficiency because OFLX in this condition, exists in protonated form. This ionic form is consequently soluble in water and remains in aqueous phase during the extraction process. At $\mathrm{pH}$ values exceeding 7.0, the formation of organic phase is not observed because of complete dissociation of hexanoic acid. Therefore, optimal pH was 6.0.

\subsubsection{Effect of sodium carbonate and sulfuric acid concentrations}

The concentrations of sodium carbonate and sulfuric acid were varied from 0.5 to $3 \mathrm{~mol} \mathrm{~L}^{-1}$ for both reagents (Fig. 3C). Low values of them were characterized by small peak areas and high RSDs due to formation of emulsion. Peak areas were increased and RSDs were decreased, with rising of sodium carbonate concentration, and then became constant at $2 \mathrm{~mol} \mathrm{~L}^{-1}$, which was selected as optimal concentration. It was found that $2.5 \mathrm{~mol} \mathrm{~L}^{-1} \mathrm{H}_{2} \mathrm{SO}_{4}$ can be considered as optimal for analysis.

\subsection{Interference effect}

The effect of the main urine components on automated EA-SSLPME coupled with HPLC-FLD determination of OFLX was also investigated. It was performed by addition of known concentration of the following possible components of urine: $\mathrm{Cl}^{-}, \mathrm{NO}_{3}^{-}, \mathrm{SO}_{4}^{2-}$, $\mathrm{HPO}_{4}^{2-}, \mathrm{NH}_{4}^{+}, \mathrm{Ca}^{2+}, \mathrm{Mg}^{2+}, \mathrm{Zn}^{2+}, \mathrm{Na}^{+}, \mathrm{K}^{+}$, urea, glycine, glucose, creatine, creatinine, as well as citric, uric and hippuric acids to $0.5 \cdot 10^{-6} \mathrm{~mol} \mathrm{~L}^{-1}$ solution of OFLX. The tolerable concentration of each taken foreign compound is considered to be less than $5 \%$ of relative error in the signal. The results are shown in Table 1. Significant interferences were found for citric acid, hippuric acid, glucose, creatine, glycine, uric acid, $\mathrm{Zn}^{2+}, \mathrm{Mg}^{2+}, \mathrm{K}^{+}, \mathrm{SO}_{4}^{2-}, \mathrm{HPO}_{4}^{2-}$ and $\mathrm{NO}_{3}^{-}$. To eliminate the interference effect of the urine components, samples were diluted 1000 folds before the analysis.

\subsection{Analytical performance}

To evaluate the feasibility of the developed EA-SS-LPME, parameters including the linear range, LOD, regression coefficient and repeatability were studied under the optimized conditions. The calibration curve constructed by plotting the peak area against five different concentrations of OFLX (Peak area $=1.40 \times 10^{6} \times\left[\right.$ concentration of OFLX in $\left.10^{-6} \mathrm{~mol} \mathrm{~L}^{-1}\right]$ ) was obtained in the range of $3 \cdot 10^{-8}-3 \cdot 10^{-6} \mathrm{~mol} \mathrm{~L}^{-1}$ with a regression coefficient equal to 0.997 . The LOD, calculated from the blank tests based on $3 \sigma$, was $1 \cdot 10^{-8} \mathrm{~mol} \mathrm{~L}^{-1}$. The method's repeatability expressed as RSD $(n=5)$ is $4.0 \%$ and $2 \%$ at $0.03 \cdot 10^{-6} \mathrm{~mol} \mathrm{~L}^{-1}$ and $3 \cdot 10^{-6} \mathrm{~mol} \mathrm{~L}^{-1}$, respectively. A univariant optimization approach was used to deeply study all the variables involved in the procedure. Although, this method requires a great number of experiments, it allows obtaining detailed information about the EA-SSLPME. A summary of the optimized conditions used is presented in Table 2. The active therapeutic concentration of OFLX in urine is from $5 \cdot 10^{-4} \mathrm{~mol} \mathrm{~L}^{-1}$ to $2 \cdot 10^{-3} \mathrm{~mol} \mathrm{~L}^{-1}$ [34]. The sample preparation of the developed method includes urine sample predilution and the obtained concentration of OFLX can be determined by the established linear range.

\subsection{Application for analysis of real samples}

The proposed procedure was applied to the analysis of human urine samples. The obtained results showed no significant differences in OFLX concentration obtained by the suggested and the method described in Section 2.5 [31]. (Table 3). Student's t-test of statistical hypotheses about the equality of means was used to test the equality of the means of the experimental data obtained by developed method and by the spectrofluorimetric method with cloud-point extraction [31]. Hypothesis about the equality of the means of the experimental data obtained by the developed method and by the spectrofluorimetric method was taken as the null hypothesis $\left(\mathrm{H}_{0}\right)$. Hypothesis about the difference of mentioned means was taken as an alternative hypothesis $\left(\mathrm{H}_{1}\right)$. The significance was taken equal to the 0.05 level. Based on the obtained results, the observed differences were not contrary to the $\mathrm{H}_{0}$ hypothesis and the obtained discrepancies with the 0.05 significance level could be considered insignificant.

\section{Conclusion}

A novel fully automated effervescence-assisted switchable solvent-based liquid phase microextraction procedure was developed and applied in the determination of fluoroquinolone antibacterial agent ofloxacin in human urine samples. The benefits of the effervescence-assisted microextraction and switchable hydrophilicity solvents microextraction have been combined. The sodium carbonate was used as the hydrophilicity modifier for fatty acid, as the effervescence agent and as the phase separation intensifier providing in-situ generation of $\mathrm{CO}_{2}$. The extraction process required only 2 min to extract analyte from $1 \mathrm{~mL}$ of sample solution and utilized only $50 \mu \mathrm{L}$ of hexanoic acid. Thus, the automated effervescence-assisted switchable solvent-based liquid phase microextraction approach can be considered as a green, rapid, simple, cheap and convenient.

\section{Acknowledgments}

This work was supported by the Russian Foundation for Basic Research (projects no. 13-03-00031-a, no. 15-33-20068, no. 1633-60137-mol_a_dk, 16-33-00037-mol_a), Scientific Grant Agency of the Ministry of Education of the Slovak Republic and the Slovak Academy of Sciences (Grant no. VEGA 1/0010/15). Scientific 
research was performed at the Center for Chemical Analysis and Materials Research and the Educational Resource Center of Research Park of St.Petersburg State University. This work was supported in part through the development of bilateral cooperation between the Slovak and Russian universities within the Operational Programme Education financed by the European Social Fund (ESF) (project ITMS 26110230084).

\section{Appendix A. Supplementary data}

Supplementary data related to this article can be found at http:// dx.doi.org/10.1016/j.aca.2015.12.004.

\section{References}

[1] A.N. Anthemidis, K.I.G. Ioannou, Recent developments in homogeneous and dispersive liquid-liquid extraction for inorganic elements determination. A review, Talanta 80 (2009) 413-421.

[2] J.M. Kokosa, Advances in solvent-microextraction techniques, Trends Anal. Chem. 43 (2013) 2-13.

[3] H.G. Liu, P.K. Dasgupta, Analytical chemistry in a drop. Solvent extraction in a microdrop, Anal. Chem. 68 (1996) 1817-1821.

[4] M.A. Jeannot, F.F. Cantwell, Mass transfer characteristics of solvent extraction into a single drop at the tip of a syringe needle, Anal. Chem. 69 (1997) 235-239.

[5] S. Pedersen-Bjergaard, K.E. Rasmussen, Liquid-liquid-liquid microextraction for sample preparation of biological fluids prior to capillary electrophoresis, Anal. Chem. 71 (1999) 2650-2656.

[6] S. Pedersen-Bjergaard, K.E. Rasmussen, Liquid-phase microextraction with porous hollow fibers, a miniaturized and highly flexible format for liquid-liquid extraction, Rev. J. Chromatogr. A 1184 (2008) 132-142.

[7] M. Ghambarian, Y. Yamini, A. Esrafili, Developments in hollow fiber based liquid-phase microextraction: principles and application, Microchim. Acta 177 (2012) 271-294.

[8] M. Rezaee, Y. Assadi, M.R.M. Hosseini, E. Aghaee, F. Ahmadi, S. Berijani, Determination of organic compounds in water using dispersive liquid-liquid microextraction, J. Chromatogr. A 1116 (2006) 1-9.

[9] M.R.K. Zanjani, Y. Yamini, S. Shariati, J.A. Jönsson, A new liquid-phase microextraction method based on solidification of floating organic drop, Anal. Chim. Acta 585 (2007) 286-293.

[10] V. Andrucha, I. Balogh, L. Kocúrová, J. Šandrejová, Five years of dispersive liquid-liquid microextraction, Appl. Spectrosc. Rev. 48 (2013) 161-259.

[11] V. Andruch, L. Kocúrová, I.S. Balogh, J. Škrlíková, Recent advances in coupling single-drop and dispersive liquid-liquid microextraction with UV-vis spectrophotometry and related detection techniques, Microchem. J. 102 (2012) $1-10$.

[12] A. Zgoła-Grzeskowiak, T. Grzeskowiak, Dispersive liquid-liquid microextraction, Trends Anal. Chem. 30 (2011) 1382-1389.

[13] Sh Dadfarnia, A.M.H. Shabani, Recent development in liquid phase microextraction for determination of trace level concentration of metals-A review, Anal. Chim. Acta 658 (2010) 107-119.

[14] G. Lasarte-Aragonés, R. Lucena, S. Cárdenas, M. Valcárcel, Effervescenceassisted dispersive liquid-liquid microextraction with extractant removal by magnetic nanoparticles, Anal. Chim. Acta 807 (2014) 61-66.

[15] G. Lasarte-Aragonés, R. Lucena, S. Cárdenas, M. Valcárcel, Use of switchable solvents in the microextraction context, Talanta 131 (2014) 645-649.

[16] G. Lasarte-Aragonés, R. Lucena, S. Cárdenas, M. Valcárcel, Use of switchable hydrophilicity solvents for the homogeneous liquid-liquid microextraction of triazine herbicides from environmental water samples, J. Sep. Sci. 38 (2015) 990-995.

[17] J.R. Vanderveen, J. Durelle, P.G. Jessop, Design and evaluation of switchablehydrophilicity solvents, Green Chem. 16 (2014) 1187-1197.

[18] X. Liu, Z. Shen, P. Wang, C. Liu, Z. Zhou, D. Liu, Effervescence assisted on-site liquid phase microextraction for the determination of five triazine herbicides in water, J. Chromatogr. A 1371 (2014) 58-64.

[19] S. Molaei, A. Saleh, V. Ghoulipour, S. Seidi, Dissolved carbon dioxide flotation: An effective way for phase separation in emulsification microextraction method, J. Chromatogr. A 1388 (2015) 280-285.

[20] E. Yilmaz, M. Soylak, Switchable solvent-based liquid phase microextraction of copper (II): optimization and application to environmental samples, J. Anal. At. Spectrom. 30 (2015) 1629-1635.

[21] H.-K. Shih, T.-Y. Shu, V.K. Ponnusamy, J.-F. Jen, A novel fatty-acid-based intube dispersive liquid-liquid microextraction technique for the rapid determination of nonylphenol and 4-tert-octylphenol in aqueous samples using high-performance liquid chromatography-ultraviolet detection, Anal. Chim. Acta 854 (2015) 70-77.

[22] I. Timofeeva, I. Khubaibullin, M. Kamencev, A. Moskvin, A. Bulatov, Automated procedure for determination of ammonia in concrete with headspace singledrop micro-extraction by stepwise injection spectrophotometric analysis, Talanta 133 (2015) 34-37.

[23] Ch Fulmes, A. Bulatov, O. Yasakov, E. Freze, A. Moskvin, Y. Dedkov, L. Moskvin, Multicommutated stepwise injection analysis as new approach for simultaneous determination of Nickel (II), Copper (II) and Zinc (II) in wet aerosols, Microchem. J. 110 (2013) 649-665.

[24] A. Bulatov, A. Petrova, A. Vishnikin, L. Moskvin, Stepwise injection spectrophotometric determination of cysteine in biologically active supplements and fodders, Microchem. J. 110 (2013) 369-437.

[25] M. Falkova, M. Pushina, A. Bulatov, G. Alekseeva, L. Moskvin, Stepwise injection spectrophotometric determination of flavonoids in medicinal plants, Anal. Lett. 47 (2014) 970-982.

[26] Ch Vakh, A. Bulatov, A. Shishov, A. Zabrodin, L. Moskvin, Determination of silicon, phosphorus, iron and aluminum in biodiesel by multicommutated stepwise injection analysis with classical least squares method, Fuel 135 (2014) 198-204.

[27] Ch Vakh, M. Falkova, I. Timofeeva, A. Moskvin, L. Moskvin, A. Bulatov, Flow analysis: a novel approach for classification, Crit. Rev. Anal. Chem. (2015), http://dx.doi.org/10.1080/10408347.2015.1087301. Article in press.

[28] E.H. Hansen, M. Miro, How flow-injection analysis (FIA) over the past 25 years has changed our way of performing chemical analyses, Trends Anal. Chem. 26 (2007) 18-26.

[29] Ch Vakh, E. Freze, A. Pochivalov, E. Evdokimova, M. Kamencev, L. Moskvin, A. Bulatov, Simultaneous determination of iron (II) and ascorbic acid in pharmaceuticals based on flow sandwich technique, J. Pharmacol. Toxicol. Methods 73 (2015) 56-62.

[30] W.R. Melcherta, B.F. Reisb, F.R.P. Rocha, Green chemistry and the evolution of flow analysis. A review, Anal. Chim. Acta 714 (2012) 8-19.

[31] H. Wu, G. Zhao, L. Du, Determination of ofloxacin and gatifloxacin by mixed micelle-mediated cloud point extraction-fluorimetry combined methodology, Spectrochim. Acta, Part A 75 (2010) 1624-1628.

[32] E.P. Serjeant, B. Dempsey, Ionization Constants of Organic Acids in Aqueous Solution, 1979. Pergamon, Oxford.

[33] M. Crespo-Alonso, V.M. Nurchi, R. Biesuz, G. Alberti, N. Spano, M.I. Pilo, G. Sanna, Biomass against emerging pollution in wastewater: Ability of cork for the removal of ofloxacin from aqueous solutions at different $\mathrm{pH}$, J. Environ. Chem. Eng. 1 (2013) 1199-1204.

[34] A.M. Pimenta, M.R. Souto, R.I. Catarino, M.F. Leal, J.L. Lima, Ofloxacin determination in urine, serum and pharmaceuticals using an automatic flow potentiometric system, Anal. Sci. 29 (2013) 893-898. 